\title{
The prevalence of Caenorhabditis elegans across 1.5 years in selected North German locations: the importance of substrate type, abiotic parameters, and Caenorhabditis competitors
}

\author{
Carola Petersen, Philipp Dirksen, Swantje Prahl, Eike Andreas Strathmann and Hinrich Schulenburg*
}

\begin{abstract}
Background: Although the nematode Caenorhabditis elegans is a major model organism in diverse biological areas and well studied under laboratory conditions, little is known about its ecology. Therefore, characterization of the species' natural habitats should provide a new perspective on its otherwise well-studied biology. The currently best characterized populations are in France, demonstrating that C. elegans prefers nutrient- and microorganism-rich substrates such as rotting fruits and decomposing plant matter. In order to extend these findings, we sampled C. elegans continuously across 1.5 years from rotting apples and compost heaps in three North German locations.

Results: C. elegans was found throughout summer and autumn in both years. It shares its habitat with the related nematode species C. remanei, which could thus represent an important competitor for a similar ecological niche. The two species were isolated from the same site, but rarely the same substrate sample. In fact, $C$. elegans was mainly found on compost and C. remanei on rotten apples, possibly suggesting niche separation. The occurrence of C. elegans itself was related to environmental humidity and rain, although the correlation was significant for only one sampling site each. Additional associations between nematode prevalence and abiotic parameters could not be established.
\end{abstract}

Conclusions: Taken together, our findings vary from the previous results for French C. elegans populations in that the considered German populations always coexisted with the congeneric species $C$. remanei (rather than C. briggsae as in France) and that C. elegans prevalence can associate with humidity and rain (rather than temperature, as suggested for French populations). Consideration of additional locations and time points is thus essential for full appreciation of the nematode's natural ecology.

Keywords: Caenorhabditis elegans, Caenorhabditis remanei, Niche separation, Competition

\section{Background}

The nematode Caenorhabditis elegans has become one of the main model organisms in biological research, where it proved of extreme value in diverse disciplines such as animal development and genetics, neurobiology and behaviour, and genome architecture and function [1]. Several specific characteristics have contributed to the nematode's popularity over the last decades, for example

\footnotetext{
*Correspondence: hschulenburg@zoologie.uni-kiel.de
Department of Evolutionary Ecology and Genetics, Zoological Institute,
Christian-Albrechts University, Am Botanischen Garten 1-9, 24118 Kiel,

* Correspondence: hschulenburg@zoologie.uni-kiel.de
Department of Evolutionary Ecology and Genetics, Zoological Institute,
Christian-Albrechts University, Am Botanischen Garten 1-9, 24118 Kiel,

*Correspondence: hschulenburg@zoologie.uni-kiel.de
Department of Evolutionary Ecology and Genetics, Zoological Institute,
Christian-Albrechts University, Am Botanischen Garten 1-9, 24118 Kiel, Germany
}

its known genome, its short generation time, the ease of obtaining isogenic lines by selfing, and the possibility to produce frozen stocks. Intriguingly, however, almost all research with this worm is done with a single wildtype strain, called N2, which has been kept in the laboratory for several decades and is known to have specifically adapted to the commonly used experimental conditions $[2,3]$. In contrast, only very little is known about the nematode's natural environment and ecology, including its life-history in the field, its seasonal abundance, global distribution, or association with other organisms. Such information may be of high value for our understanding of 
C. elegans biology: the exact and true function of numerous genes, many of which are still of unknown function, may only be revealed if the species' natural conditions are taken into account.

Over the last couple of years, an increasing number of studies began to assess different aspects of the ecology of this nematode, yielding a first overview of C. elegans in its natural habitat. C. elegans has been found in most parts of the world [4], although only rarely in the tropics [5]. In temperate regions, it is common and often coexists with its congeneric relatives $C$. remanei and C. briggsae [5]. In the past, C. elegans was usually considered to inhabit soils [6-8], although even then it was already known from other substrates such as decaying mushrooms, leaf litter, garden compost [4,9], or invertebrates [10-14], usually in anthropogenic environments [15]. More recent studies focused on compost heaps and rotten fruits and showed that proliferating C. elegans populations can be found regularly in these substrates $[6,12,14,16,17]$. The predominant stage of $C$. elegans found in compost heaps is the dauer stage. Recently rotten fruits and decomposing plant stems were found to contain populations of all stages including populations without any dauer larvae [17].

The aim of our study was to investigate the population dynamics of C. elegans and other Caenorhabditis species at different locations in Northern Germany across time. We additionally aimed at evaluating in how far the presence of $C$. elegans is related to abiotic parameters such as atmospheric temperature, which is expected to affect fitness of ectotherms [18,19], including C. elegans under laboratory conditions [20,21]. Furthermore, we also considered additional environmental parameters that may affect nematode proliferation such as the amount of rain fall, environmental humidity and $\mathrm{pH}$. In order to identify suitable substrates for such long-term analyses, we initially screened high numbers of decaying mushrooms, different parts of Arum maculatum, and a variety of decomposing fruits, plants as well as compost samples from different locations in Northern Germany. Compost and rotten apples contained Caenorhabditis most frequently. Therefore, for the current study, we specifically focused our sampling efforts on these two substrates. Here, we now present our results from 18 months continuous sampling of compost and rotting apples from three North German locations.

\section{Methods}

\section{Sampling sites and types of samples}

Sampling was carried out continuously once to twice every month from July 2011 to December 2012. We focused on three North German locations (Kiel, Münster, and Roxel) and two substrate types (compost, rotten apples), which we found in initial pilot studies to contain high frequencies of Caenorhabditis nematodes. In Kiel the samples were collected in the botanical garden $\left(54^{\circ}\right.$ $20^{\prime} \mathrm{N}$ and $10^{\circ} 06^{\prime} \mathrm{E}$ ) from three large compost heaps and additionally from rotten apples collected from a locally separated apple heap and from below nearby apple trees. In Münster, samples were collected in a meadow of the city's farming museum $\left(51^{\circ} 56^{\prime} \mathrm{N}\right.$ and $\left.7^{\circ} 36^{\prime} \mathrm{E}\right)$ where a compost heap and apple trees are found in close vicinity. Roxel $\left(51^{\circ} 57^{\prime} \mathrm{N}\right.$ and $\left.7^{\circ} 32^{\prime} \mathrm{E}\right)$ is a village close to Münster, where the samples were taken from three small compost heaps in a private garden.

Two substrate types were collected (compost and rotting apples). Compost was sampled from all three locations. In Kiel three big compost heaps ranging from fresh to old compost were used. The fresh compost consisted of plant material including grass, leaves, parts of bushes, parts of various plants and soil. The old compost consisted mainly of soil, but also contained some plant material. The compost heaps were mixed three times during the sampling period, once each in October 2011, May 2012, and October 2012. In Münster there was one compost heap on a meadow. The composition was similar to the fresh compost in Kiel, although it additionally contained straw and feces of sheep. This compost was not stirred during the considered sampling period. The compost in Roxel consisted of three small heaps of different ages in mesh cages. The fresh compost with mainly plant parts but also some organic garbage from the owners was only slightly degraded, whereas the older composts consisted mainly of soil and remaining parts of leaves and trees. The Roxel composts were stirred and mixed exactly once during the sampling period, namely in May 2012. In Kiel and Münster, rotting apples were additionally available. In Kiel, rotten apples could be sampled during the entire year from a specific apple compost heap. In Münster, the number of apples was limited, as they were left to rot under the trees in a meadow, on which sheep were kept continuously.

\section{Collection of samples and isolation of nematodes}

Compost samples were taken from up to $15 \mathrm{~cm}$ depth of the compost heaps. Rotten apples were picked up from the ground. Compost and apples were collected in plastic bags. For most months and especially for the compost heaps, we collected at least six independent samples per site, and the distance between each of these was at least $50 \mathrm{~cm}$ for the Roxel compost and at least $100 \mathrm{~cm}$ for all other sites, ensuring at least some independence of the samples from a particular location and day. All samples were kept at approximately $10^{\circ} \mathrm{C}$ until they were processed in the laboratory. Sample processing was completed within 24 hours after collection to minimize changes in the present nematode developmental stages and also in the species composition of associated organisms. Approximately 
5 g compost material or alternatively four to five apple pieces were distributed around a spot of $150 \mu \mathrm{l}$ of an overnight culture of Escherichia coli OP50 on $9 \mathrm{~cm}$ peptone free medium (PFM) agar plates [22]. The nutrient-limited PFM agar was used to ensure standardized conditions across sampling dates and substrate types, because it minimizes growth of naturally associated microbes. As these naturally associated microbes are likely to vary across time and substrate and as they may also differ in their ability to grow on the standard nutrient-rich laboratory growth media, usage of such nutrient-rich media could lead to a substantial change in microbial composition and in turn nematode abundance. For each of the collected samples (e.g., a particular apple or a particular compost soil sample) we prepared exactly one sampling plate. The plates were checked for the presence of worms using a dissecting scope. Nematodes resembling Caenorhabditis were transferred individually onto new $6 \mathrm{~cm}$ PFM plates within the first five hours using a platinum picker. The plates were again checked for nematodes after 24 hours and after three to seven days. With few exceptions, we transferred no more than ten individual worms per sample. Based on this sampling scheme, we considered the worms isolated from different samples to be independent findings for a particular location, day, and substrate type, while the worms from one specific sample may be of common origin. We still assessed several worms per sample, in order to test whether different Caenorhabditis species coexist in one piece of substrate and are thus likely to interact with each other in nature.

\section{Species identification using microscopy and PCR}

The isolated worms were kept for several days on plates. Further consideration of nematodes was based on the following criteria (see also previous Caenorhabditis sampling approaches in $[6,12,17,22])$ : (i) Nematodes should produce offspring; (ii) they should show morphological features characteristic for Caenorhabditis [22]; and (iii) they should test positive in diagnostic genus- or speciesspecific PCRs [6,22]. For the latter, DNA of Caenorhabditis candidates was isolated by transferring one to five worms into $20 \mu \mathrm{l} 1 \times$ PCR-buffer, including $1 \mu$ l Proteinase $\mathrm{K}(10 \mathrm{mg} / \mathrm{ml})$. Worms were frozen for at least one hour at $-80^{\circ} \mathrm{C}$ to break up tissue, digested for one hour at $50^{\circ} \mathrm{C}$ and boiled for 15 minutes at $95^{\circ} \mathrm{C}$ in a PCR machine (biolab products, LabCycler). For the speciesspecific primer pairs (Table 1), $1 \mu$ l of the DNA was subjected to the following reaction conditions: $95^{\circ} \mathrm{C}$ for 2 min followed by 35 cycles of $95^{\circ} \mathrm{C}$ for $1 \mathrm{~min}$, primerspecific annealing temperatures for $0.5 \mathrm{~min}$ (Table 1) and $72^{\circ} \mathrm{C}$ for $1 \mathrm{~min}$, and at the very end a final extension step at $72^{\circ} \mathrm{C}$ for $10 \mathrm{~min}$. Conditions for Caenorhabditis genus-specific primers were $95^{\circ} \mathrm{C}$ for 2 min followed by 40 cycles of $95^{\circ} \mathrm{C}$ for $1 \mathrm{~min}, 70^{\circ} \mathrm{C}$ for $0.75 \mathrm{~min}$ and $72^{\circ} \mathrm{C}$ for $2.25 \mathrm{~min}$, and additionally a final extension step at $72^{\circ} \mathrm{C}$ for $10 \mathrm{~min}$ (Table 1 ). The exact amplification conditions for all species-specific PCRs and also the primers specific for $C$. elegans and C. remanei were optimized by us to ensure unequivocal identification of the three most commonly encountered Caenorhabditis taxa (Additional file 1: Figure S1). For C. elegans, species identity was confirmed using two diagnostic primer pairs: One targeting a variable part of the recently duplicated immunity gene $n l p-30$, which is exclusively present in $C$. elegans [23], and the other targeting the zeel-1/peel-1 compatibility locus [24]. Species identity was further verified for 21 randomly chosen $C$. elegans and 16 randomly chosen $C$. remanei natural isolates using crossing experiments with males from characterized laboratory strains. For 24 randomly chosen C. briggsae isolates, species identity was additionally confirmed by Sanger sequencing of the ribosomal ITS2 region, using the primers of the Caenorhabditis-diagnostic PCR (Table 1). The initial plates that contained worms tested positive

Table 1 Diagnostic primers used for identification of Caenorhabditis species or genus

\begin{tabular}{|c|c|c|c|c|c|c|}
\hline Primer name & Primer sequence $5^{\prime}-3^{\prime}$ & Anneal $\mathrm{T}^{\mathrm{a}}$ & Target region & Specificity & Size ${ }^{\mathbf{b}}$ & Reference \\
\hline nlp30-F & ACACATACAACTGATCACTCA & $55^{\circ} \mathrm{C}$ & $n / p-30$ & C. elegans & $154 \mathrm{bp}$ & This study \\
\hline nlp30-R & TACTITCCCCATCCGTATC & & & & & \\
\hline zeel/peel-leftF & CTGAAGCATGCCGGATTTAT & $59^{\circ} \mathrm{C}$ & Region with zeel-1 + peel-1 & C. elegans & $940 \mathrm{bp}$ & [24] and this study \\
\hline zeel/peel-leftR & TCCGTCCAATATTCAATCGAC & & & & & \\
\hline Cre-ITS2-F1 & TTGTCGGGCGGCATTGGGGCT & $65^{\circ} \mathrm{C}$ & Ribosomal ITS2 & C. remanei & $300 \mathrm{bp}$ & This study \\
\hline Cre-ITS2-R4 & CGTCGTCTTCCTTACCCCGAA & & & & & \\
\hline Cbriggsae- $F$ & GAACCTGCGAGTGCATG & $56^{\circ} \mathrm{C}$ & $g / p-1$ & C. briggsae & $302 \mathrm{bp}$ & [22] \\
\hline Cbriggsae- $R$ & CCGTCTGCAAACGAACGGGC & & & & & \\
\hline KK5.8S-1 & CTGCGTTACTTACCACGAATTGCARAC & $70^{\circ} \mathrm{C}$ & Ribsomal ITS2 & Caenorhabditis & $2008 \mathrm{bp}$ & [14] \\
\hline KK28S-4 & GCGGTATTTGCTACTACCAYYAMGATCTGC & & & & & \\
\hline
\end{tabular}


for Caenorhabditis were subsequently used to bleach and freeze these strains for future studies.

For an analysis of proliferating nematode populations, we only considered worms, which were isolated and transferred individually to separate plates within five hours after sample processing (see above). At this point, developmental stage of the worms was scored. Thereafter, the worms were allowed to reach adulthood. If the adult worms showed the morphological characteristics of Caenorhabditis, they were subjected to the diagnostic PCR tests. The final results table only included worms belonging to the Caenorhabditis genus.

\section{Measurement of abiotic variables}

Atmospheric temperature and humidity were recorded directly during sampling with a digital multi-purpose thermo-hygrometer (TFA Dostmann GmbH \& Co. KG). The measurement was done directly above the collected substrates in a distance of 5 to $10 \mathrm{~cm}$. The $\mathrm{pH}$ of collected compost and apples was measured in the laboratory using a mobile pH-meter (PCE-228, PCE Deutschland GmbH). For this purpose compost samples were mixed in the plastic bag and the electrode was brought into direct contact with the sample. In the rotten apples the measurement was done in an apple part that represented a decomposition stage similar to the pieces used for worm isolation. Additionally the average amount of rain per month for Kiel and Münster was obtained from Germany's National Meteorological Service, the Deutscher Wetterdienst (DWD). As Münster and Roxel are close to each other, the data for rain in Münster was taken for both locations.

\section{Statistics}

The current study explores Caenorhabditis occurrence across time in different substrates and locations. Due to the time-consuming sampling scheme, we did not include replication for a particular substrate type and location. Temporal dynamics in species prevalence is thus summarized using absolute numbers and percentages. Two types of statistical tests were applied with caution for each a particular substrate type and location separately, in order to (i) assess overall variation in species prevalence, and (ii) relate the proportion of nematodecontaining samples with any of the measured abiotic parameters. For the first type of analyses, we used frequency tests, namely the Fisher exact test, for pairwise comparisons of species abundance (number of independent samples containing a particular species) across the entire sampling period and for each substrate type and location separately. For the second type of analyses, we assessed the presence of correlations between the proportion of samples with either C. elegans or C. remanei and each of the measured abiotic factors temperature, humidity, rain and $\mathrm{pH}$, using a Spearmans-rank-test (for each substrate type and location separately). Only data sets with at least five sampling months in a row were taken into account for the correlation analysis. All statistical tests were performed with the program JMP version 9.0.2 (SAS Institute Inc.). For each of the analyses, multiple testing was accounted for by adjusting the significance level using the false discovery rate (FDR; [25]). Graphs were produced with R version 2.15.2 and Microsoft Office Excel 2007.

\section{Results}

Caenorhabditis species diversity and substrate association in Northern Germany

We assessed a total of 663 independent samples for presence of Caenorhabditis nematodes $(498 \times$ compost, $165 \times$ rotten apple; Table 2; Additional file 2: Figure S2, Additional file 3: Figure S3, Additional file 4: Figure S4; Additional file 5: Table S1 and Additional file 6: Table S2). Based on our sampling scheme, we obtained isolates of three Caenorhabditis species, namely C. elegans, C. rema$n e i$, and $C$. briggsae, but no other Caenorhabditis taxon. The three species were found in different quantities, whereby C. elegans was generally most common. In detail, 149 of the collected 498 compost samples (30\% of the 498 compost samples) contained Caenorhabditis nematodes. At all sampling sites, compost samples contained significantly more often C. elegans than C. remanei or C. briggsae (Table 3). 63 out of the 165 collected rotten apple samples (38\% of the 165 apples) harboured Caenorhabditis worms. For the apples from Kiel, C. remanei was significantly more common than C. elegans or C. briggsae (Table 3). Surprisingly, C. elegans was never found on rotten apples in Kiel. Although both compost and rotten apples in general contained each of the three species, coexistence of at least two species was only occasionally observed: Five compost samples (1\% of the total 498 compost samples) contained both C. elegans and C. remanei, while a different set of five compost samples (1\%) harboured both C. elegans and C. briggsae. C. remanei and $C$. briggsae were never isolated from the same substrate sample.

\section{Seasonal abundance}

Compost could be collected all year long at all sampling sites and contained Caenorhabditis worms between July 2011 and January 2012 and between May 2012 and December 2012 (Figure 1; Additional file 6: Table S2). C. elegans was most abundant in Kiel compost in September 2011, in Münster compost in October 2012, and in Roxel compost in September and December 2012. Overall late summer and autumn seem to be the time periods with highest $C$. elegans prevalence (Figure 1). C. remanei was found in compost from August to November 2011, in August 2012 and from October to December 2012. 
Table 2 Total number of independent samples and overall species prevalence

\begin{tabular}{|c|c|c|c|c|c|c|c|}
\hline \multirow[t]{2}{*}{ Origin } & \multirow[t]{2}{*}{ Total samples ${ }^{a}$} & \multicolumn{2}{|l|}{ C. elegans } & \multicolumn{2}{|l|}{ C. remanei } & C. briggsae & \multirow[b]{2}{*}{ Ind } \\
\hline & & Positive samples $^{\mathbf{b}}$ & $\operatorname{lnd}^{c}$ & $\overline{\text { Positive samples }}$ & Ind. & $\overline{\text { Positive samples }}$ & \\
\hline Kiel apple & 123 & $0(0)$ & 0 & $41(0.33)$ & 173 & $0(0)$ & 0 \\
\hline Münster apple & 42 & $6(0.14)$ & 32 & $10(0.24)$ & 42 & $6(0.14)$ & 15 \\
\hline Kiel compost & 170 & $30(0.18)$ & 114 & $7(0.04)$ & 23 & $5(0.03)$ & 12 \\
\hline Münster compost & 129 & $27(0.21)$ & 124 & $1(0.01)$ & 6 & $4(0.03)$ & 10 \\
\hline Roxel compost & 199 & $70(0.35)$ & 348 & $4(0.02)$ & 5 & $1(0.01)$ & 1 \\
\hline
\end{tabular}

${ }^{a}$ Total number of independent samples per substrate type and location.

${ }^{\mathrm{b}}$ Number and proportion (in brackets) of independent samples that contained the respective Caenorhabditis species.

${ }^{\mathrm{c}}$ Total number of individuals isolated for the respective species from the indicated substrate type and location.

This species showed highest abundance in Kiel in August 2011, in Münster in September 2011 and in Roxel in October 2012. C. briggsae was only rarely found, with peak frequencies in Kiel compost in August 2011 and in Münster compost in October 2011. In Roxel C. briggsae was only found once in August 2012.

Rotten apples were available in Kiel all year long and in Münster always from July to November. C. elegans was only found on rotten apples in Münster from September to November 2012 with highest abundance in October 2012 (Figure 1; Additional file 6: Table S2). C. remanei was found on rotten apples continuously between August 2011 and December 2012. Peak frequencies were recorded for Kiel in October 2011 and for Münster in November 2011 (Figure 1). C. briggsae was only found on apples in Münster, where it was common in October 2011.

\section{Variation in the presence of proliferating Caenorhabditis populations}

After individual collection of samples, these were kept at approximately $10^{\circ} \mathrm{C}$ up to 24 hours before analysis on PFM plates. Within one to five hours after transfer onto plates, the samples were specifically assessed for indications of proliferating nematode populations, for example the presence of stages other than the long-lasting dauer

Table 3 Fisher Exact test on the variation of species abundance per substrate type and location ${ }^{a}$

\begin{tabular}{llll}
\hline Origin & CE vs. CR & CE vs. CB & CR vs. CB \\
\hline Kiel apple & $<\mathbf{0 . 0 0 0 1 *}$ & $>0.99$ & $<\mathbf{0 . 0 0 0 1 *}$ \\
Münster apple & 0.4052 & $>0.99$ & 0.4052 \\
Kiel compost & $<\mathbf{0 . 0 0 0 1 *}$ & $<\mathbf{0 . 0 0 0 1 *}$ & 0.7703 \\
Münster compost & $<\mathbf{0 . 0 0 0 1 *}$ & $<\mathbf{0 . 0 0 0 1 *}$ & 0.3701 \\
Roxel compost & $<\mathbf{0 . 0 0 0 1 *}$ & $<\mathbf{0 . 0 0 0 1 *}$ & 0.3718 \\
\hline
\end{tabular}

${ }^{a}$ The frequencies used for this analysis are given in Table 2. The three Caenorhabditis species are compared pairwise. Abbreviations: $C E C$. elegans, $C R$ $C$. remanei, $C B C$. briggsae. The false discovery rate was used to account for multiple testing and the remaining significant $P$-values (at $a<0.05$ ) are given in bold and indicated by an asterisk. stage. In the case of C. elegans, proliferating populations were found in several compost samples from all three locations, especially Roxel compost and Münster apples (Table 4). For C. remanei, proliferating populations were identified for rotten apples, especially from Kiel, and also compost (Table 4). C. briggsae was always isolated as a dauer stage during the early one to five hours-period.

\section{The influence of abiotic factors on the occurrence of C. elegans and C. remanei}

The correlation between the occurrence of C. elegans and C. remanei and the abiotic factors atmospheric temperature, humidity, rain and $\mathrm{pH}$ was analyzed for each sampling site and substrate type separately. The Spearman's rank test showed a significant positive correlation of humidity with, on the one hand, the proportion C. eleganscontaining compost samples from Münster and, on the other hand, the proportion of C. remanei-containing apple samples from Kiel (Figure 2, Tables 5 and 6). Additionally, in Kiel rain was correlated positively with C. elegans prevalence in compost (Figure 2, Table 5). C. elegans prevalence also correlated negatively with temperature in Münster apples, although in this case correlations were based on only few sampling dates and thus possibly unreliable (Table 5). None of the other considered correlations was significant or showed at least a statistical trend (Tables 5 and 6).

\section{Discussion}

We here provide one of the few long-term ecological studies on C. elegans, one of the main model species in biological research. Our study covers an 18-month period and three independent sampling sites, thus yielding a broader perspective on $C$. elegans ecology than most previous studies $[6,12,14,16,17]$. Similar ecological information is rare for most of the classical genetic model taxa like yeast, Drosophila melanogaster or mice in spite of its potential importance for in-depth understanding of the comprehensive laboratory-derived information on the species' biologies. 


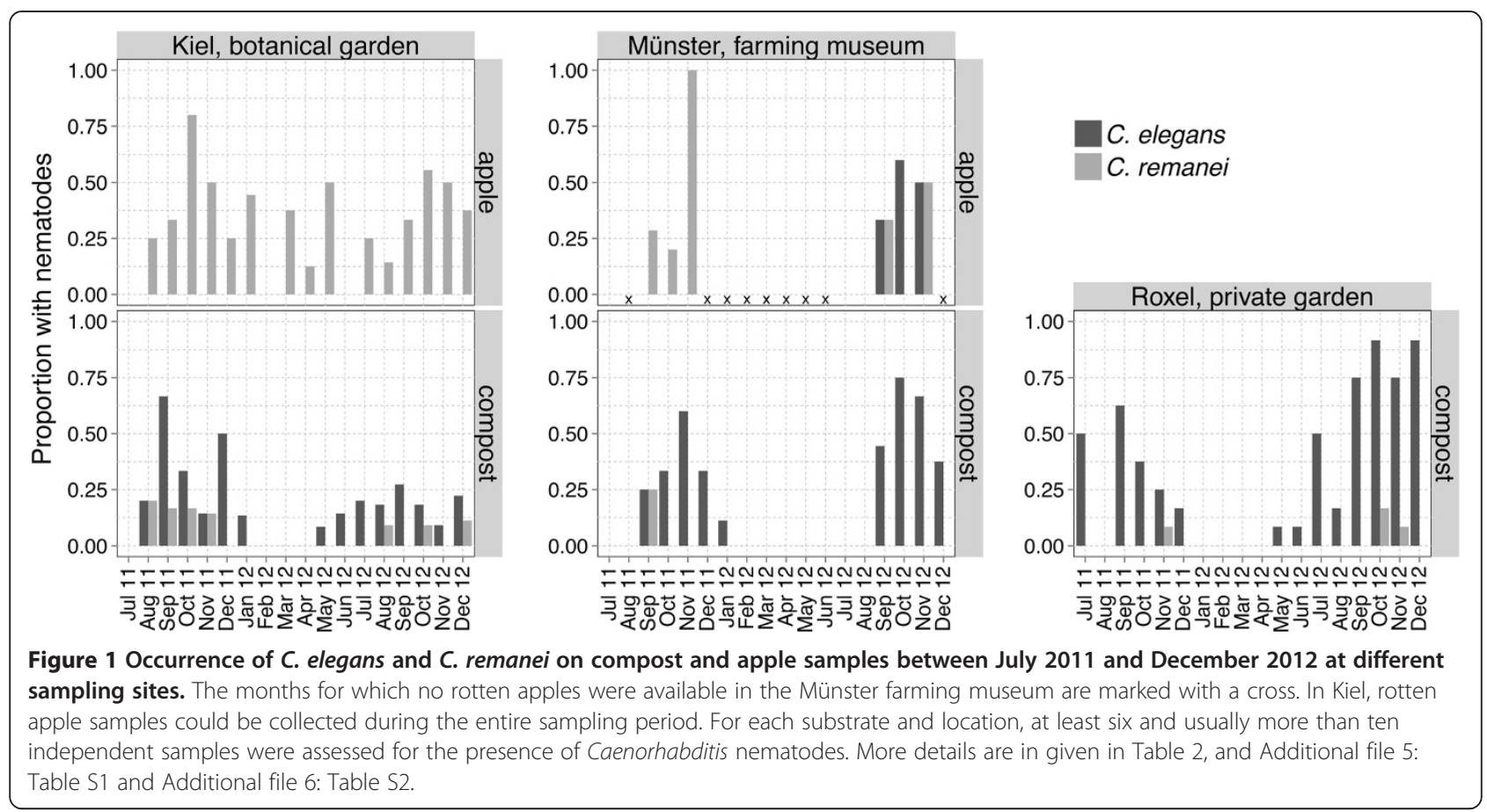

High prevalence of $C$. elegans and C. remanei in Northern Germany

Our results generally confirm the recent study from mainland France that the diversity of Caenorhabditis species seems to be low at individual locations, at least in Central Europe [17], in contrast to the higher taxon diversity observed for a tropical rainforest in French Guiana [26]. Across the three North German sampling sites, we mainly found $C$. elegans and $C$. remanei, whereas $C$. briggsae was only occasionally found in small numbers. Other Caenorhabditis species could not be detected. Curiously, C. remanei appears to be restricted to Germany and neighboring regions (e.g., Elsace in Eastern France) $[15,17]$, even though at a global scale it is found across a variety of temperate locations, for example in North America and Japan [15]. One possible reason for the species limited distribution in Europe is competition with a species with a similar ecological niche. Consistent with this idea, the congeneric C. briggsae seems to be very common in Europe - except for the German locations with $C$. remanei. This is best documented for the comprehensively sampled locations in France, revealing high prevalence of $C$. elegans and $C$. briggsae, but absence of $C$. remanei [17]. The Caenorhabditis species may additionally compete with other nematode taxa, which were regularly seen (yet not further characterized) in the same substrate samples.

\section{Substrate preference of different Caenorhabditis species}

In general C. elegans may show a hemerophile life-style and thus occurs more frequently in places influenced by humans [15]. Such anthropogenic habitats probably

Table 4 Proliferating Caenorhabditis populations: Number of independent Caenorhabditis-containing samples and worms isolated within few hours upon substrate processing

\begin{tabular}{|c|c|c|c|c|c|c|c|c|c|c|c|c|}
\hline \multirow[t]{3}{*}{ Origin } & \multicolumn{4}{|c|}{ C. elegans } & \multicolumn{4}{|c|}{ C. remanei } & \multicolumn{4}{|c|}{ C. briggsae } \\
\hline & \multicolumn{2}{|c|}{ Samples $^{a}$} & \multicolumn{2}{|c|}{ Individuals $^{\mathbf{b}}$} & \multicolumn{2}{|c|}{ Samples } & \multicolumn{2}{|c|}{ Individuals } & \multicolumn{2}{|c|}{ Samples } & \multicolumn{2}{|c|}{ Individuals } \\
\hline & Total $^{c}$ & Non-D ${ }^{d}$ & Total $^{c}$ & Non-D ${ }^{d}$ & Total & Non-D & Total & Non-D & Total & Non-D & Total & Non-D \\
\hline Kiel apple & 0 & 0 & 0 & 0 & 15 & 15 & 54 & $40(7,2,31)$ & 0 & 0 & 0 & 0 \\
\hline Münster apple & 4 & 4 & 12 & $7(3,1,3)$ & 3 & 3 & 8 & $8(0,0,8)$ & 3 & 0 & 3 & 0 \\
\hline Kiel compost & 21 & 5 & 75 & $6(6,0,0)$ & 2 & 2 & 11 & $11(3,1,7)$ & 3 & 0 & 9 & 0 \\
\hline Münster compost & 18 & 5 & 94 & $10(3,1,6)$ & 0 & 0 & 0 & 0 & 2 & 0 & 3 & 0 \\
\hline Roxel compost & 48 & 20 & 169 & $36(14,4,18)$ & 3 & 3 & 4 & $4(1,0,3)$ & 0 & 0 & 0 & 0 \\
\hline
\end{tabular}

${ }^{a}$ Number of independent samples from which C. elegans, C. remanei or C. briggsae were isolated within few hours after sample processing.

${ }^{\mathrm{b}}$ Number of individual worms isolated within few hours after sample processing.

'Total numbers irrespective of developmental stage.

${ }^{\mathrm{d}}$ Numbers for only non-dauer stages with further details given in brackets in the following order: L1-L3, L4, adult. 


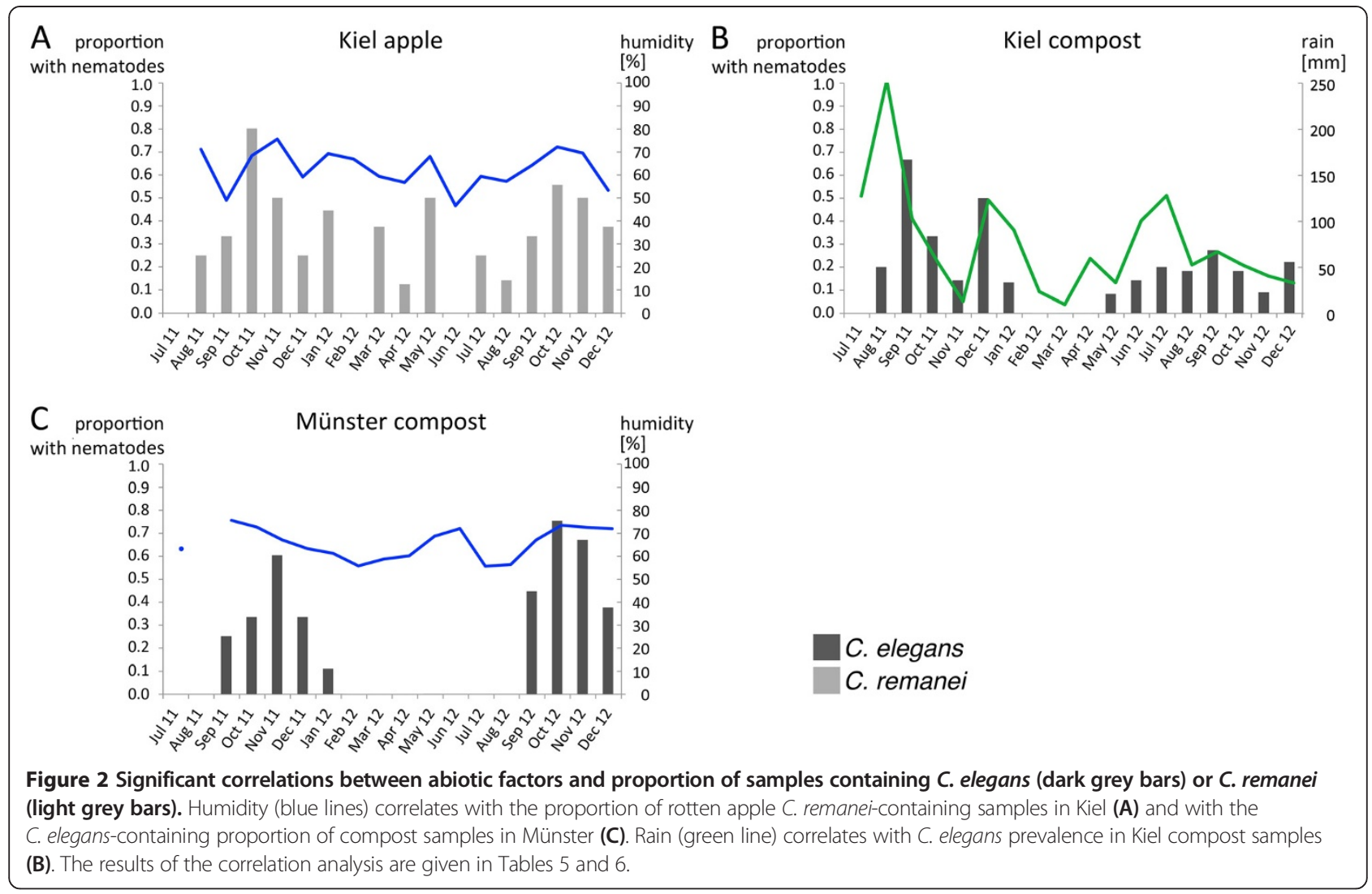

Table 5 Correlations between mean proportion of C. elegans-containing samples and abiotic factors

\begin{tabular}{llllll}
\hline Location & Substrate & $\begin{array}{l}\text { Correlating abiotic } \\
\text { factor }\end{array}$ & Rho $^{\boldsymbol{a}}$ & $\mathbf{N}$ & $\boldsymbol{P}^{\boldsymbol{b}}$ \\
\hline Kiel & Compost & Temperature & 0.2203 & 17 & 0.3955 \\
& & $\mathrm{pH}$ & -0.1072 & 0.8328 \\
& & Humidity & 0.0069 & 0.8881 \\
Münster & Apple & Rain & 0.1580 & $\mathbf{0 . 0 0 6 0 ^ { * }}$ \\
& & Temperature & -0.8416 & 9 & $\mathbf{0 . 0 0 4 4 ^ { * }}$ \\
& & pH & 0.6337 & 0.0669 \\
& & Humidity & 0.5446 & 0.1295 \\
Münster & Compost & Rain & 0.0594 & 0.8793 \\
& & Temperature & -0.4596 & 17 & 0.0634 \\
& & pH & -0.1683 & 0.5184 \\
& & Humidity & 0.6296 & $\mathbf{0 . 0 0 6 8}$ \\
& & Rain & 0.1463 & 0.5753 \\
Roxel & Compost & Temperature & 0.1299 & 17 & 0.6193 \\
& & pH & -0.2845 & 0.2684 \\
& & Humidity & -0.2684 & 0.2976 \\
& & Rain & 0.2882 & 0.2620 \\
\hline
\end{tabular}

${ }^{a}$ Correlations were assessed with a non-parametric Spearman's rank test. ${ }^{b}$ Significance levels were corrected for multiple comparisons using the false discovery rate; the resulting significant correlations at $\alpha<0.05$ are given in bold and indicated by an asterisk. provide a more constant supply of nutrient-rich organic material and thus microbial food throughout the year. Curiously, in previous studies, C. elegans was most often found as dauer with no reproductive activity in compost heaps [12,27]. Even though dauers were usually the most frequent stage in our study, a considerable proportion of samples did contain proliferating $C$. elegans populations (Table 3). It would be important in the future to evaluate which specific characteristics of the compost samples favour nematode proliferation.

C. elegans could not be isolated from any rotten apple from Kiel and was also absent from the 2011 apple collection from Münster. In 2012, however, this nematode was found on some of the Münster apples, in all cases with proliferating populations (Table 3 ). These particular apples were collected very close to the compost heap that harboured C. elegans. Therefore, it is possible that migration from the compost heap accounted for the nematode's presence on apples. In general, the rare occurrence of $C$. elegans on apples in Northern Germany contrasts with observations in France, where C. elegans is especially abundant on decaying apples [17]. At the same time, North German apples contained high frequencies of $C$. remanei, which was more or less absent from France [17]. Moreover, both species were occasionally isolated from the same substrate sample and are 
Table 6 Correlations between mean proportion of C. remanei-containing samples and abiotic factors

\begin{tabular}{|c|c|c|c|c|c|}
\hline Location & Substrate & $\begin{array}{l}\text { Correlating abiotic } \\
\text { factor }\end{array}$ & $R h o^{a}$ & $\mathbf{N}$ & $P^{b}$ \\
\hline \multirow[t]{4}{*}{ Kiel } & Apple & Temperature & -0.1394 & 17 & 0.5936 \\
\hline & & $\mathrm{pH}$ & -0.1727 & & 0.5073 \\
\hline & & Humidity & 0.6179 & & $0.0082^{*}$ \\
\hline & & Rain & -0.3702 & & 0.1436 \\
\hline \multirow[t]{4}{*}{ Kiel } & Compost & Temperature & 0.1869 & 17 & 0.4726 \\
\hline & & $\mathrm{pH}$ & -0.1072 & & 0.6822 \\
\hline & & Humidity & 0.0069 & & 0.9791 \\
\hline & & Rain & 0.1580 & & 0.5447 \\
\hline \multirow[t]{4}{*}{ Münster } & Apple & Temperature & -0.4265 & 9 & 0.2523 \\
\hline & & $\mathrm{pH}$ & 0.0783 & & 0.8412 \\
\hline & & Humidity & 0.3917 & & 0.2972 \\
\hline & & Rain & -0.5919 & & 0.0932 \\
\hline \multirow[t]{4}{*}{ Münster } & Compost & Temperature & 0.1531 & 17 & 0.5575 \\
\hline & & $\mathrm{pH}$ & -0.4082 & & 0.1038 \\
\hline & & Humidity & 0.4085 & & 0.1035 \\
\hline & & Rain & 0.0510 & & 0.8458 \\
\hline \multirow[t]{4}{*}{ Roxel } & Compost & Temperature & -0.1937 & 17 & 0.4563 \\
\hline & & $\mathrm{pH}$ & -0.1365 & & 0.6013 \\
\hline & & Humidity & -0.1882 & & 0.4695 \\
\hline & & Rain & -0.2491 & & 0.3350 \\
\hline
\end{tabular}

${ }^{a}$ Correlations were assessed with a non-parametric Spearman's rank test. ${ }^{b}$ Significance levels were corrected for multiple comparisons using the false discovery rate; the resulting significant correlations at $\alpha<0.05$ are given in bold and indicated by an asterisk.

thus likely to interact directly with each other in nature. Therefore, it is conceivable that $C$. remanei may outcompete $C$. elegans on rotten apples, forcing $C$. elegans to use other substrate types in the North German locations.

\section{Influence of abiotic conditions on the occurrence of Caenorhabditis species}

To obtain a first impression of the influence of abiotic parameters, we related the occurrence of C. elegans and C. remanei to temperature, humidity, rain fall, and $\mathrm{pH}$. Temperature is likely of importance in this context $[18,19]$, as previously isolated, natural C. elegans strains differ in their temperature preference, which appears to underlie natural variation in fitness [20,21]. Our current results do not support these previous observations, as we did not identify a positive association between atmospheric temperature and nematode occurrence. The potential influence of temperature may thus either be weak, obscured by additional factors, and/or missed by our approach, which did not allow us to obtain measurements at the micro-scale, possibly most relevant for the nematodes.

Interestingly, temperatures in spring generally appear suitable for both Caenorhabditis species, yet nematodes could usually not be isolated during this period, possibly as a result of nematode population dynamics during winter, which are currently unknown. It is possible that during winter the nematodes move to deeper compost layers with more favourable temperatures or die out in these substrates, followed by recolonization in spring or summer. Our sampling scheme did not allow us to evaluate these alternatives, because sampling depth was kept constant at up to $15 \mathrm{~cm}$ over the 18 month-period to ensure comparability of sampling results across time.

Humidity and rain were additionally expected to affect Caenorhabditis distributions. Moisture was shown for other nematode species to influence migratory dynamics [28]. Moisture may also be important to prevent desiccation, a known cause of death for non-dauer stages of $C$. elegans under laboratory conditions, and to enhance presence and proliferation of microbial food. For our samples, we were able to identify a significant positive correlation between humidity and C. elegans on compost in Münster and between humidity and C. remanei on rotten apples in Kiel. Furthermore rain was correlated with C. elegans occurrence in compost from Kiel. Humidity may thus have some influence on Caenorhabditis distributions. In the future, it would be important to investigate in more detail the consequences of humidity variations, not only in the air as measured by us, but also at much smaller scale directly in the substrates.

In contrast, we could not identify a statistically relevant association with $\mathrm{pH}$. This result may be due to wide $\mathrm{pH}$ tolerance levels, which were previously reported for C. elegans under laboratory conditions [29].

\section{Additional factors}

Biotic factors are likely to play a central role in shaping Caenorhabditis distributions in nature. In this context, substrate availability, occurrence of either food or pathogenic microbes, and also the presence of competitors and predators should be of particular importance. This is supported by the recent observation of substantial natural variation in putative immunity genes across French C. elegans populations [30]. Within the framework of our study, these factors were not directly assessed and we will briefly discuss their potential importance below.

One basic requirement for proliferation is the availability of suitable substrates. The quality of compost depends on the addition of new material that is left to rot and rotting organic material is only available for a limited time before its complete disintegration. It is known that fresh compost and rotting fruits contain higher numbers of $C$. elegans compared to older compost or soil [12]. Regular compost mixing may thus alter availability of suitable substrates. For the considered composts, this factor may have had only a minor influence during the sampling period, because composts had either not 
been mixed at all (Münster farming museum), or only once in May 2012 (Roxel private garden); or three times (October 2011, May 2012, and October 2012; Kiel botanical garden), where it did not seem to have an obvious effect on nematode abundance (Figure 1). Substrate availability may also play an important role in winter, where usually little plant material is added from gardens for decomposition, and it could also be influenced by other animals such as the sheep in the Münster farming museum. At this location, sheep were maintained continuously on the same meadow, from which we collected apples and where they most likely ate fruits, possibly limiting the time during which rotting apples were available as substrate. This may explain why C. elegans was not found on Münster apples in 2011 but only in 2012 and, in this case, only on apples separated from the sheep by a fence, although at the same time, this factor did not prevent high C. remanei prevalence on apples in both years.

The presence and diversity of natural microbes are most likely of central importance for worm fitness, either as food or pathogens. Their exact role under natural conditions is currently unexplored. At least under laboratory conditions, different food bacteria were previously shown to vary in their effect on nematode reproductive rates [31], while C. elegans also shows significant natural variation in its resistance towards the possibly naturally associated pathogens Bacillus thuringiensis or Serratia marcescens $[32,33]$. Similarly, as indicated above, there may be substantial competition between different Caenorhabditis species and also between these and other nematodes if these overlap in their ecological niches. Finally, predators and vectors may additionally influence the population biology of natural Caenorhabditis populations. We found several invertebrate species to coexist with our Caenorhabditis nematodes such as mites, isopods, springtails, flies, spiders, earwigs, beetles, ants, snails and slugs (unpublished data). Some of these are likely predators of Caenorhabditis worms such as the nematophagous mites [22]. Others have been proposed to act as vectors, enhancing nematode migration [15]. Humans may additionally influence nematode distributions by providing stable microbe-rich habitats, by actively distributing worms through transport of organic material, and also by destruction of the more natural habitats, thus enhancing their presence in anthropogenically influenced locations.

\section{Conclusion}

C. elegans and C. remanei can be found regularly in compost or rotten apples in North German locations with $C$. elegans being more prevalent in compost and $C$. remanei in apples, possibly as a consequence of competition between the two taxa. The exact range of factors influencing the species' distributions are yet unknown. Our analysis suggests at least some influence from certain abiotic factors like humidity and rain. It is likely that biotic factors are additionally a major determinant of Caenorhabditis prevalence. Their detailed analysis, especially the influence of different food microbes, pathogens, predators, and vectors, deserves particular attention in the future.

\section{Additional files}

Additional file 1: Figure S1. Exemplary results for species-diagnostic PCRs for (A) C. remanei and C. briggsae, (B) C. elegans (two diagnostic PCRs). The order of samples is always DNA of C. elegans (1), C. remanei (2), C. briggsae (3), and negative control (4). The outer lanes contain a $100 \mathrm{bp}-\mathrm{DNA}$ ladder. Lenghts of $1000 \mathrm{bp}$ and either $300 \mathrm{bp}$ or $150 \mathrm{bp}$ are indicates on the far left. The specificity of the different targets of the diagnostic PCRs are indicated at the top of each panel (see also Table 1 of the main text).

Additional file 2: Figure S2. Locations and samples in the botanical garden in Kiel. Rotten apples were mainly collected from an apple compost (A). Compost was sampled from three big heaps (B) containing plant material in different stages of degradation. Samples were collected in plastic bags and placed on plates in the laboratory (C). C. elegans was found in different compost samples (D-F) while C. remanei was mainly found on rotten apples $(G, H)$.

Additional file 3: Figure S3. The farming museum in Munster. A compost heap (A) and apple trees (B) are located on the same meadow. Sheep have access to both, compost and apples. Rotten apples have been collected below the trees. C. elegans was found in different compost samples (C, D) and rarely on rotten apples (E). C. remanei was mainly found on rotten apples $(\mathrm{F}-\mathrm{H})$ and only a few times on compost.

Additional file 4: Figure S4. Compost samples from a private garden in Roxel. The compost is stored in three mesh cages (A). The cages contain plant material in different stages of decomposition (B-G). C. elegans has been found regularly in compost samples from all cages. Other Caenorhaditis species were rarely found.

Additional file 5: Table S1. Complete list of newly isolated Caenorhabditis strains. The list contains information on strain name, internal strain code, independence of samples, exact location of origin, substrate from which nematodes were isolated, and date of sampling.

Additional file 6: Table S2. Detailed overview of prevalence of C. elegans and C. remanei across the three North German locations. The list provides information on number and proportion of samples per substrate, location, and month.

Competing interests

The authors declare that they have no competing interests.

\section{Authors' contributions}

CP carried out the sampling, processed the samples, isolated worms and drafted the manuscript. PD helped with the sampling and statistical analysis. EAS helped with sampling, processing of the samples and abiotic measurements. SP helped with sampling and abiotic measurements. HS carried out the statistical analysis, helped to draft the manuscript and supervised the project. All authors read and approved the final manuscript.

\section{Acknowledgements}

We thank Wei Chen, Christina Griebner, Fabian Peters, Stefanie Rohwer (all Kiel, Germany) and Barbara Hasert (Münster, Germany) for help with sampling and technical assistance. We are also grateful to Elke Berner and the team of the Mühlenhof (Münster, Germany) for support while sampling in the farming museum in Münster. CP, PD and HS were funded by the ESF Eurocores EEFG project NEMADAPT (DFG grant SCHU 1415/11-1). The

funders had no role in study design, data collection and analysis, decision to publish, or preparation of the manuscript.

Received: 15 November 2013 Accepted: 30 January 2014

Published: 6 February 2014 
References

1. Fitch DHA: Evolution: an ecological context for C. elegans. Curr Biol CB 2005, 15:R655-R658.

2. McGrath PT, Xu Y, Ailion M, Garrison JL, Butcher RA, Bargmann Cl: Parallel evolution of domesticated Caenorhabditis species targets pheromone receptor genes. Nature 2011, 477:321-325.

3. Weber KP, De S, Kozarewa I, Turner DJ, Babu MM, de Bono M: Whole genome sequencing highlights genetic changes associated with laboratory domestication of C. elegans. PLoS One 2010, 5:e13922.

4. Hodgkin J, Doniach T: Natural variation and copulatory plug formation in Caenorhabditis elegans. Genetics 1997, 146:149-164.

5. Félix M-A, Braendle C: The natural history of Caenorhabditis elegans. Curr Biol CB 2010, 20:R965-R969.

6. Haber M, Schüngel M, Putz A, Müller S, Hasert B, Schulenburg H: Evolutionary history of Caenorhabditis elegans inferred from microsatellites: evidence for spatial and temporal genetic differentiation and the occurrence of outbreeding. Mol Biol Evol 2004, 22:160-173.

7. Nørhave NJ, Spurgeon D, Svendsen C, Cedergreen N: How does growth temperature affect cadmium toxicity measured on different life history traits in the soil nematode Caenorhabditis elegans? Environ Toxicol Chem 2012, 31:787-793.

8. Troemel ER, Félix M-A, Whiteman NK, Barrière A, Ausubel FM: Microsporidia are natural intracellular parasites of the nematode Caenorhabditis elegans. PLOS Biol 2008, 6:2736-2752.

9. Sivasundar A, Hey J: Population genetics of Caenorhabditis elegans: the paradox of low polymorphism in a widespread species. Genetics 2003, 163:147-157.

10. Baird SE: Natural and experimental associations of Caenorhabditis remanei with Trachelipus rathkii and other terrestrial isopods. Nematology 1999, 1(5):471-475.

11. Barrière $A$, Félix M-A: Natural variation and population genetics of Caenorhabditis elegans. In WormBook. Edited by The C. elegans Research Community. 2005. doi:10.1895/wormbook.1.43.1, http://www.wormbook.org.

12. Barrière A, Félix M-A: Temporal dynamics and linkage disequilibrium in natural Caenorhabditis elegans populations. Genetics 2007, 176:999-1011.

13. Caswell-Chen EP: Revising the standard wisdom of $C$. elegans natural history: ecology of longevity. Sci Aging Knowl Environ 2005, 2005:pe30-pe30.

14. Kiontke KC, Félix M-A, Ailion M, Rockman MV, Braendle C, Pénigault J-B, Fitch DH: A phylogeny and molecular barcodes for Caenorhabditis, with numerous new species from rotting fruits. BMC Evol Biol 2011, 11:339.

15. Kiontke K, Sudhaus W: Ecology of Caenorhabditis species. In WormBook. Edited by The C. elegans Research Community. 2006. doi:10.1895/ wormbook.1.37.1, http://www.wormbook.org.

16. Blaxter $M$, Denver DR: The worm in the world and the world in the worm. BMC Biol 2012, 10:57

17. Félix M-A, Duveau F: Population dynamics and habitat sharing of natural populations of Caenorhabditis elegans and C. briggsae. BMC Biol 2012, 10:59.

18. Dell Al, Pawar S, Savage VM: Systematic variation in the temperature dependence of physiological and ecological traits. Proc Natl Acad Sci USA 2011, 108:10591-10596.

19. Huey RB, Berrigan D: Temperature, demography, and ectotherm fitness. Am Nat 2001, 158:204-210

20. Anderson JL, Albergotti L, Proulx S, Peden C, Huey RB, Phillips PC: Thermal preference of Caenorhabditis elegans: a null model and empirical tests. J Exp Biol 2007, 210:3107-3116.

21. Anderson $J$, Albergotti L, Ellebracht B, Huey RB, Phillips PC: Does thermoregulatory behavior maximize reproductive fitness of natural isolates of Caenorhabditis elegans? BMC Evol Biol 2011, 11:157.

22. Barrière A, Félix M-A: Isolation of $C$. elegans and related nematodes. In WormBook. Edited by The C. elegans Research Community. 2006. doi:10.1895/wormbook.1.115.1, http://www.wormbook.org.

23. Pujol N, Zugasti O, Wong D, Couillault C, Kurz CL, Schulenburg H, Ewbank J J $\mathrm{JJ}$ : Anti-fungal innate immunity in $\mathrm{C}$. elegans is enhanced by evolutionary diversification of antimicrobial peptides. PLOS Pathog 2008, 4:e1000105.

24. Seidel HS, Rockman MV, Kruglyak L: Widespread genetic incompatibility in C. elegans maintained by balancing selection. Science 2008, 319:589-594.

25. Benjamini $Y$, Hochberg $Y$ : Controlling the false discovery rate: a practical and powerful approach to multiple testing. J R Stat Soc B 1995, 57:289-300
26. Félix M-A, Jovelin R, Ferrari $C$, Han S, Cho YR, Andersen EC, Cutter AD, Braendle C: Species richness, distribution and genetic diversity of Caenorhabditis nematodes in a remote tropical rainforest. BMC Evol Biol 2013, 13:10.

27. Barrière A, Félix M-A: High local genetic diversity and low outcrossing rate in Caenorhabditis elegans natural populations. Curr Biol 2005, 15:1176-1184.

28. Dos Santos CN, de Souza LS, Quinelato SB, Do Couto MCM, Pinheiro J, Rodrigues ML, De A: Seasonal dynamics of cyathostomin (Nematoda Cyathostominae) infective larvae in Brachiaria humidicola grass in tropical southeast Brazil. Vet Parasitol 2011, 180:274-278.

29. Khanna N, Cressman CP 3rd, Tatara CP, Williams PL: Tolerance of the nematode Caenorhabditis elegans to $\mathrm{pH}$, salinity, and hardness in aquatic media. Arch Environ Contam Toxicol 1997, 32:110-114.

30. Volkers RJ, Snoek LB, Hubar CJ, Van H, Coopman R, Chen W, Yang W, Sterken MG, Schulenburg H, Braeckman BP, Kammenga JE: Geneenvironment and protein-degradation signatures characterize genomic and phenotypic diversity in wild Caenorhabditis elegans populations. BMC Biol 2013, 11:93.

31. Avery L, Shtonda BB: Food transport in the C. elegans pharynx. J Exp Biol 2003, 206:2441-2457.

32. Schulenburg $H$, Müller $\mathrm{S}$ : Natural variation in the response of Caenorhabditis elegans towards Bacillus thuringiensis. Parasitology 2004 128:433-443.

33. Schulenburg H, Ewbank JJ: Diversity and specificity in the interaction between Caenorhabditis elegans and the pathogen Serratia marcescens. BMC Evol Biol 2004, 4:49.

doi:10.1186/1472-6785-14-4

Cite this article as: Petersen et al:: The prevalence of Caenorhabditis elegans across 1.5 years in selected North German locations: the importance of substrate type, abiotic parameters, and Caenorhabditis competitors. BMC Ecology 2014 14:4.

\section{Submit your next manuscript to BioMed Central and take full advantage of:}

- Convenient online submission

- Thorough peer review

- No space constraints or color figure charges

- Immediate publication on acceptance

- Inclusion in PubMed, CAS, Scopus and Google Scholar

- Research which is freely available for redistribution 